This item was submitted to Loughborough's Research Repository by the author.

Items in Figshare are protected by copyright, with all rights reserved, unless otherwise indicated.

\title{
Investigating what level of visual information inspires trust in a user of a highly automated vehicle
}

PLEASE CITE THE PUBLISHED VERSION

https://doi.org/10.1016/j.apergo.2020.103272

PUBLISHER

Elsevier

VERSION

AM (Accepted Manuscript)

PUBLISHER STATEMENT

This paper was accepted for publication in the journal Applied Ergonomics and the definitive published version is available at https://doi.org/10.1016/j.apergo.2020.103272.

\section{LICENCE}

CC BY-NC-ND 4.0

\section{REPOSITORY RECORD}

Ma, Rachel H.Y., Andrew Morris, Paul Herriotts, and Stewart Birrell. 2020. "Investigating What Level of Visual Information Inspires Trust in a User of a Highly Automated Vehicle”. Loughborough University. https://hdl.handle.net/2134/12952142.v1. 


\title{
Investigating what level of visual information inspires trust in a user of a highly automated vehicle
}

\author{
Rachel H.Y. Ma ${ }^{1}$, *Andrew Morris ${ }^{1}$, Paul Herriotts ${ }^{2}$, Stewart Birrell ${ }^{2}$ \\ ${ }^{1}$ Loughborough Design School, Loughborough University, Loughborough, United Kingdom. \\ (rhyma@outlook.com; *a.p.morris@lboro.ac.uk) \\ ${ }^{2}$ Coventry University, Coventry, United Kingdom. (ad2611@coventry.ac.uk; ad2998@coventry.ac.uk)
}

\begin{abstract}
The aim of this research is to investigate whether visual feedback alone can affect a driver's trust in an autonomous vehicle, and in particular, what level of feedback (no feedback vs. moderate feedback vs. high feedback) will evoke the appropriate level of trust. Before conducting the experiment, the Human Machine Interfaces ( $\mathrm{HMI}$ ) were piloted with two sets of six participants (before and after iterations), to ensure the meaning of the displays can be understood by all. A static driving simulator experiment was conducted with a sample of 30 participants (between 18 and 55). Participants completed two pre-study questionnaires to evaluate previous driving experience, and attitude to trust in automation. During the study, participants completed a trust questionnaire after each simulated scenario to assess their trust level in the autonomous vehicle and HMI displays, and on intention to use and acceptance. The participants were shown 10 different driving scenarios that lasted approximately 2 minutes each. Results indicated that the 'high visual feedback' group recorded the highest trust ratings, with this difference significantly higher than for the 'no visual feedback' group $(U=.000 ; p=<0.001<\alpha)$ and the 'moderate visual feedback' group $(U=.000 ; p=<0.001<\alpha)$. There is an upward inclination of trust in all groups due to familiarity to both the interfaces and driving simulator over time. Participants' trust level was also influenced by the driving scenario, with trust reducing in all displays during safety verses non-safetycritical situations.
\end{abstract}

Keywords: Autonomous vehicles; trust; visual feedback; HMI; driving simulator. 


\section{Introduction}

In the past decades, technological advancements have led to the development of Advanced DriverAssistance Systems (ADAS) which actively assist the driver with the primary driving task, for example Lane Keeping System (LKS) and Adaptive Cruise Control (ACC). The consistent development in automated (aka driverless or self-driving) technology is likely to lead to their introduction into our society in the near-future, with IHS Automotive (2016; cited in IHS Markit, 2016) predicting there will be approximately 21 million automated vehicles sold globally in 2035. Automated Driving (AD) systems can lower emissions and congestions, reduce accidents and increase safety, reduce drivers' workload and improve travelling experience if human is removed out of the driving equation in everyday driving situations (Balfe et al., 2015; Fagnant \& Kockelman, 2015; Wadud et al., 2016). To achieve these potential positive outcomes, developing an error-free AD system is of importance, but is also determined by the level of acceptance of the drivers and society today.

Trust plays an important role in influencing an individual's inclination to use the autonomous system. Trust is referred to "as the attitude that an agent will help achieve an individual's goals in a situation characterised by uncertainty and vulnerability" (Lee \& See, 2004). The authors highlight that a driver must fully trust an automation to achieve a positive outcome. Trust is said to facilitate the human-human relationship, but also in human-machine association (Sheridan; 1975; Sheridan \& Hennessy, 1984). However, Parasuraman and Riley (1997) propose that a user's trust level of the automation can cause misuse, disuse or abuse. Finding the suitable drivers' trust level is therefore required to ensure acceptance and adoption of the AD systems.

Previous research highlighted factors such as system transparency, technical competence, communicating uncertainty information and perceived usefulness can affect the level of trust in a driver (Choi \& Ji, 2015; Beller et al., 2013; Helldin et al, 2013.) Choi and Ji (2015) discussed that system transparency, technical competence and situation management are found to be important elements that can affect the trust level in drivers. They suggested that providing information to drivers about the way autonomous vehicles work can enhance driver insight on automation. It is also suggested that driver's intention to accept or reject autonomous vehicle is determined by the perceived usefulness and trust. Furthermore, according to Beller et al.'s (2013) study, drivers that were presented with an uncertainty information (a symbol with an uncertain expression) displayed quicker and safer responses in safety critical failure conditions. They proposed that more trust and acceptance was found when an uncertainty symbol is presented compared with the control group. These findings were replicated by Helldin et al. (2013), who studied similar interest on how uncertainty can impact driver's trust in an automated driving scenario. Similar findings were found; in takeover situations, drivers had more trust when uncertainty information was provided and they were more likely to carry out secondary tasks while driving and displaying trust in the automation, compared to a control group (Helldin et al., 2013). Lately, researchers have directed their focus to understand how providing knowledge information of the vehicles' capabilities 
and limitations of the AD systems can support drivers' trust level (Khastgir et al., 2018). Findings show that calibrating trust with knowledge is necessary in the dynamic environment to ensure safe use and reduce the likelihood of misuse due to distrust (Khastgir et al., 2018; Parasuraman and Riley, 1997).

Parasuraman and Riley (1997) defined automation as "the execution by a machine agent of a function that was previously carried out by a human". With the rapid development in vehicle technology, many in-vehicle functions that were carried out by a human before are now controlled by the vehicle. SAE, J3016 (2018) is used to categorise the level of automation in vehicles. This is a six-level classification system, grounded on the level of human interference required. This system ranges from level 0 - no driving automation, where the driver is fully in control of the dynamic driving task in all circumstances, to level 5 - full driving automation, where the system performs all dynamic driving tasks without the need of human control in all circumstances.

Although it has been suggested that providing clear driver-automation communication can significantly increase the trustworthiness of automation (Choi \& Ji, 2015), finding the optimal balance between the amount of information and trust is important to prevent adverse effects as giving excessive information can increased the cognitive workload of the drivers (Lyu et al., 2017; Manawadu et al., 2018; Piechulla et al., 2003). Banks and Stanton (2016) highlight that delivering a transparent human-machine interface (HMI) display can enhance driver trust in automation. Verberne et al. (2012) suggest that providing feedback of the current automation status to the environment can potentially increase the level of trust in the driver. However, providing the right level of feedback for each user within an automated vehicle is also essential, as different users will have different information expectations and preferences (Ulahannan et al., 2020b). The findings suggested that it is essential for the drivers to understand what the vehicle is doing and why, and keeping the drivers informed about the vehicle's condition is significant. Moreover, Oliveira et al. (2018) found that drivers prefer to monitor the vehicle's state and its actions during their low speed autonomous pod ride. However, although current researches have indicated that intelligent visual displays can assist in inspiring trust in automation (Haeuslschmid et al., 2017; Oliveira et al., 2018), much of the HMI related studies (Banks \& Stanton, 2016; Miller et al.,2016; Haeuslschmid et al., 2017) are often presented in conjunction with auditory elements, such as human-like voice or the sound of beep.

Current research fails to address whether a visual-only interface alone can provide adequate information to deliver a sufficient level of trust to drivers of automated vehicles. As part of the investigation of trust in autonomous vehicles, it will be interesting to recognise whether visual interface alone will play an important part in improving users' perception of trust in automation. It is, therefore, important to examine how trust in autonomous vehicle changes with the different level of visual-only feedback in order to predict effects that may worsen or promote the acceptance of autonomous vehicle. 


\section{Method}

To investigate user's acceptance of autonomous vehicle, a static driving simulator was set up to display different real-world driving situations through video presentation (see Figure 3). The participants were asked to visualise themselves in an autonomous vehicle while driving scenarios were presented to them. The study utilised a between-group design with different levels of visual feedback given to the participants depending on their assigned group. There were three groups - no feedback, moderate visual feedback and high visual feedback. Following the end of each video, a trust questionnaire (see section 2.6.2) was given to measure the participant's feelings of trust about the autonomous vehicle in that past video.

\subsection{Sampling Strategies}

Since autonomous vehicle design is still a relatively new subject, there is currently a lack of guidance that provides clear information and direction in relation to drivers in an autonomous vehicle. A user will still be required to be seated at the driver's seat for the experiment and an assumption is therefore made grounded on the definition of a level 4 autonomous vehicle provided by the SAE, J3016 (2018); the user of the autonomous vehicle will require a full driving license as they may be requested to intervene by the automated vehicle. This means that it will affect those individuals between the age of 17 to 80 who drive in the UK. Furthermore, it is assumed that those who have previously driven, in the UK with or without a UK driving licence, will have a prior and solid knowledge of the UK Highway Traffic Code.

A mixture of convenience and snowball sampling approaches was used to recruit 30 participants. Convenience sampling is a method used to recruit participants that are conveniently available and are in close proximity to the researcher. Snowball sampling is a sampling technique where existing participants recruit future participants from their connections. These methods were selected as they enable the collection of primary data in a time-effective manner. The non-probability sampling allows the recruitment of those participants that match the required characteristics. Furthermore, an independent group design was used to achieve the objective in comparing between the three different feedback levels.

\subsection{Participants}

A total of 30 participants participated in the experiment, with equal weighting in males and females. Table 1 shows a detailed breakdown of participant demographics. The participants were counter balanced into 3 groups of 10 , with 5 males and 5 females in each.

\begin{tabular}{|l|l|}
\hline Information & Participants data \\
\hline Gender & 15 (Male), 15 (Female) \\
\hline Age & $12(18-25), 9(26-30), 1(31-40), 5$ (41-50), 3 (50-55) \\
\hline Driving Experience & 4 (1-2 years), 3 (2-3 years), 2 (4-5 years), 21 (5+ years) \\
\hline
\end{tabular}




\begin{tabular}{|l|l|}
\hline Average miles per week & $\begin{array}{l}12 \text { (<100 miles), 10 (100-200 miles), 3 (200-300 miles), } 3 \text { (300-400 } \\
\text { miles), 2 (500+ miles) }\end{array}$ \\
\hline Vehicle Transmission & 20 (Manual), 10 (Automatic) \\
\hline
\end{tabular}

Table 1. Breakdown of participant demographics.

\subsection{Videos of Driving Scenarios}

A static driving simulator at the Loughborough University Design School was used in this research. The driving scenarios were projected onto a wall that was approximately $3 \mathrm{~m}$ in front of the driver's seat. Ten videos, each lasting approximately 2 minutes, of different driving scenarios (see Table 2) were used, which was pre-recorded using a dashboard camera. These videos were selected to cover a range of different scenarios. Only road and engine sounds could be heard in the videos, aiming to create an autonomous atmosphere.

\begin{tabular}{|c|l|l|}
\hline $\begin{array}{c}\text { Video } \\
\text { No. }\end{array}$ & Driving Scenarios & \multicolumn{1}{|c|}{ Description } \\
\hline 1 & $\begin{array}{l}\text { Exiting Business } \\
\text { Park }\end{array}$ & $\begin{array}{l}\text { Vehicle leaving a business park; speed limit 20mph; pedestrian } \\
\text { crossing on-road; cyclist presence; roundabouts; dry road condition; } \\
\text { minimal traffic. }\end{array}$ \\
\hline 2 & Dual Carriageway & $\begin{array}{l}\text { Busy suburban roundabout junction; dual carriageway; speed limit } \\
\text { 40mph; speed cameras, dry road condition. }\end{array}$ \\
\hline 3 & Small village & $\begin{array}{l}\text { Single carriageway; small village; speed limit 30mph; narrow bridge, } \\
\text { dry road condition. }\end{array}$ \\
\hline 4 & Town Centre & $\begin{array}{l}\text { Town centre; speed limit 20mph; busy roads; roundabout; high } \\
\text { pedestrian level; traffic lights, dry road condition. }\end{array}$ \\
\hline 5 & Single Carriageway & $\begin{array}{l}\text { Single carriageway; speed limit 50mph; roundabouts; low level of } \\
\text { traffic, dry road condition. }\end{array}$ \\
\hline 6 & $\begin{array}{l}\text { Moderate Motorway } \\
\text { Traffic }\end{array}$ & $\begin{array}{l}\text { Entering motorway; speed limit 70mph; dry road condition, moderate } \\
\text { traffic; exiting motorway at next junction. }\end{array}$ \\
\hline 8 & Residential Area & $\begin{array}{l}\text { Residential area; speed limit 30mph; dry road condition, vehicles } \\
\text { parked in road; required vehicle to pull out into opposite lane. }\end{array}$ \\
\hline 9 & Blind Corners & $\begin{array}{l}\text { Residential area; speed limit 30mph; dry road condition, vehicles } \\
\text { parked in road; on-coming vehicle wanting to pull out; two blind } \\
\text { corners; roundabout. }\end{array}$ \\
\hline 10 & $\begin{array}{l}\text { High Motorway onto } \\
\text { Traffic }\end{array}$ & $\begin{array}{l}\text { Merging onto motorway; speed limit 70mph; high traffic level, dry road } \\
\text { condition. }\end{array}$ \\
\hline $\begin{array}{l}\text { Motorway; speed limit 70mph; dry road condition, other vehicles } \\
\text { merging onto motorway; high traffic level; exiting motorway at next } \\
\text { junction. }\end{array}$ \\
\hline
\end{tabular}

Table 2. Main characteristics of the driving videos used in this study.

The driving videos were presented to each participant in the same order as shown in Table 2. Due to the practical limitations of the study design, the order of the videos could not be randomised.

\section{$2.4 \quad$ HMI Design}

The HMI displays were designed by the researchers based on the driving scenarios videos. The researcher aimed to create a simple, low-fidelity set of HMI displays as this is less time-consuming and does not require specialised skills and resources. The researchers followed the usability heuristics 
principles (Nielsen, 1994). In order to eliminate the potential outcome of HMI design being a confounding factor on user trust, before conducting the user trial it was essential to test whether users understood the meaning of the displays presented to them to eliminate the possibility of distrust due to mis-interpretation of the display rather than distrust in the vehicle.

A pre-study investigation involved a one-to-one interview that lasted approximately 15 minutes. The aims of this were to reduce potential bias so that one participant's decision would not be affected by other participant's answers. Six participants were sampled using the convenience sampling method. Each participant was required to be a holder of a full driving licence to ensure they understood the UK Highway traffic signs. The participants were given a group of display diagrams and were asked to match them up with a set of phrases and screenshots of the driving scenarios videos. Three sets of displays were given to them:

- Set 1 - UK traffic signs

- Set $2-$ What the vehicle can see

- $\quad$ Set 3 - What the vehicle will do

The process was observed by the researcher and following the completion of the card sorting activity, a brief conversation was carried out to gain feedback from the participants about their thoughts and opinions of the displays.

This testing led to the redesign of the road by adding contrasting flooring colour to differentiate traffic direction to aid directionality of the displays, rewording displays to provide clearer explanation between different meanings of displays and adding the front of vehicle to indicate its location in relation to the diagram. Furthermore, it also led to the iteration of the "waiting for a clear route" display from a clock sign to a red traffic congestion sign. With these exceptions, no other HMI displays appeared to cause confusion to participants. These changes were then presented back to the six participants and were found to be accepted by all. Similar methodology was then carried out with a new set of six participants recruited through convenience sampling method. The outcome of the one-to-one interviews after the iterations were presented was that the diagrams were much clearer, and all participants were observed to have completed all three sets without any wrong answers. Examples of the final HMI design that was presented to the participants can be seen in Figure 1 below. 


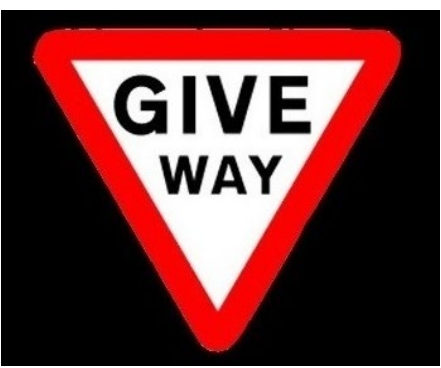

a. Give way (Set 1 - UK Traffic Sign)

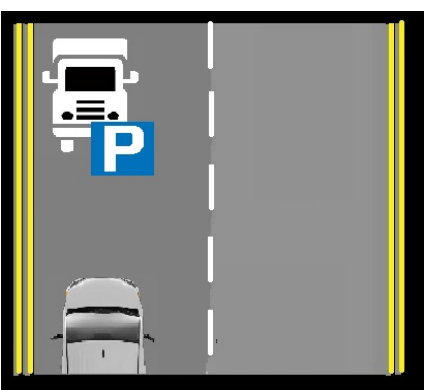

b. Vehicle parked in lane (Set 2 - What the vehicle can see)

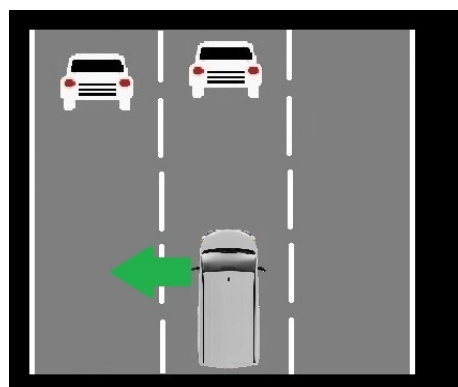

c. Vehicle changing lane (changing to the left lane) (Set 3 What the vehicle will do)

Figure 1. Examples of final HMI design presented to the participants.

The new HMI displays were used to create the feedback interface which would update in accordance with the conditions in the driving scenarios. For example, the Give Way sign would be presented when the vehicle approached a give way line.

\subsection{Equipment}

The study was setup in a static driving simulator that was implemented by a Nissan NV200 vehicle. A Sony VPL-CS1 LCD data projector was used to display the various driving scenarios directly in front of the windscreen. Road and engine noise are played back over a Fujitsu 2.0CH speaker PS-130 which were placed on both sides of the driver's seat. Furthermore, Microsoft Paint and Adobe Premiere Pro were used to create and edit the HMI displays that were then presented on an Apple iPad Air. An iPad app - 'Duet Display', was used to connect with the computer and acted as a second monitor. VLC Media Player was used to playback the videos of driving scenarios through the computer, mirrored onto the projector, and HMI displays onto the iPad, simultaneously. The iPad display was placed at the location of the vehicle's instrument panel (see Figure 2), with either:

- Group 1: No feedback - No HMI display was provided.

- Group 2: Moderate feedback - displaying Set 1 UK traffic signs and Set 2 What the vehicle can see.

- Group 3: High feedback - displaying Set 1 UK traffic signs, Set 2 What the vehicle can see and Set 3 What the vehicle will do. 


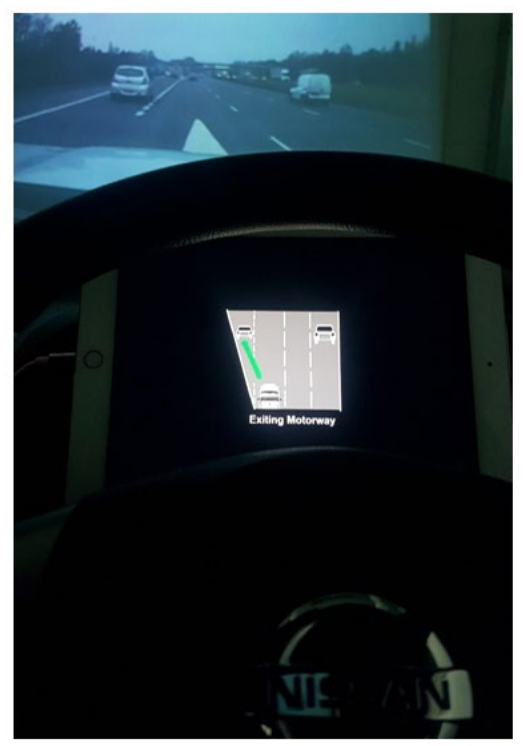

Figure 2. A photo showing an HMI display presented by the iPad at the location of the vehicle's instrument panel.

The Nissan vehicle was positioned at an appropriate distance away from the wall. The projector was placed on top of the vehicle to allow the projection to be displayed onto the wall directly in front of the windscreen (see Figure 3). This aims to increase the realistic application of the experiment when driving scenarios were presented. The vehicle was sectioned off with large grey panels to reduce environmental disturbance and direct participants' concentration onto the projected area (see Figure 3). The systems were controlled wirelessly by the researcher at the back of the vehicle, with a laptop connected to the iPad and a projector. Figure 4 shows the setup of the experiment in detail.
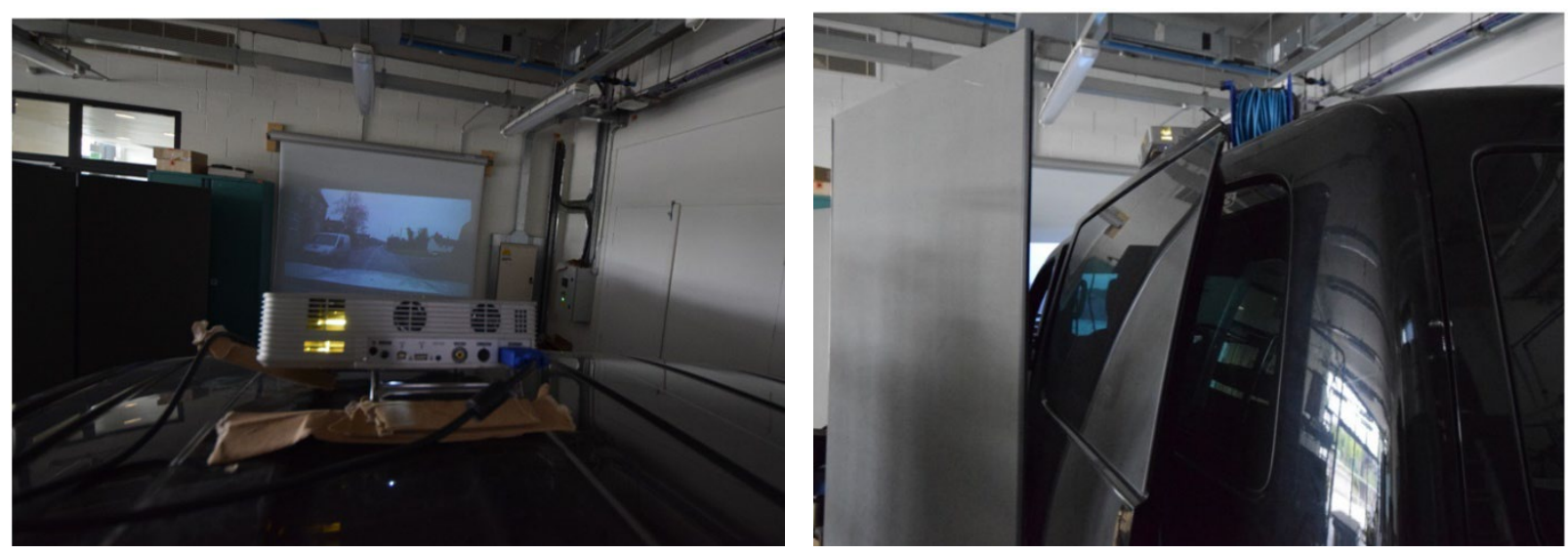

Figure 3. Simulator used in this study. The projector was placed above the Nissan vehicle to allow the projection to be displayed onto the wall (left) and large grey panels blocking the vehicle's windows were used to prevent environmental distraction (right). 


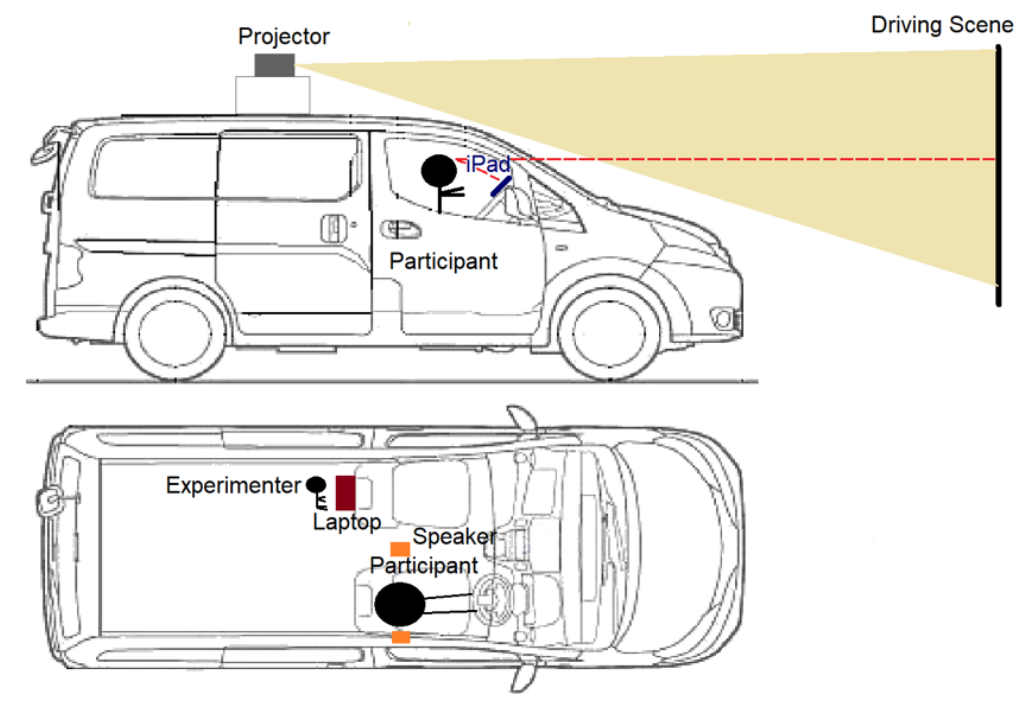

Figure 4. A diagram showing the setup of the experiment.

\subsection{Measurement Methods}

\subsubsection{Pre-Study Questionnaires}

Two pre-study questionnaires were collected prior to the start of the experiment. A demographic questionnaire was used to collect information about participants' details and previous driving experience. The second questionnaire used a 5-point Likert scale (strongly disagree, disagree, neutral, agree, strongly agree) as it enhances response quality (Babakus \& Mangold, 1992). The demographic questionnaire helped to create a personal profile for each participant about their personality and attitude towards trusting automations. Both questionnaires aimed to help explain any abnormal results if present.

\subsubsection{Trust Scale}

Since the nature of the study involves examining subjective feelings, the evaluation is therefore based on using questionnaires. Jian et al. (2000) constructed this multi-faceted measurement method through three stages of development. Firstly, the word elicitation phase involves selecting a set of words that are associated with trust and distrust. Secondly, the questionnaire stage includes examining how these words are closely related to assess the level of similarity between trust and distrust for humanhuman and human-automated systems. Finally, the paired comparison stage contains a comparison of pairs of words. The findings proposed that two different scales for trust and distrust are not necessary as they are thought to be at opposite ends of the spectrum. Additionally, the authors stated that the concept between human-human and human-machine are often found to be parallel. Consequently, the findings from these three stages were then collected and developed into a trust scale that are widely used in today's research (Miller et al.,2016; Haeuslschmid et al.,2017; Banks \& Stanton, 2016; Helldin et al.,2013; Verberne et al., 2012). In this study, Jian et al.'s (2000) Trust in Automated System questionnaire was rephrased (from 'system' to 'autonomous vehicle'). 
To assess the level of trust drivers, eight additional questions were added to the Jian et al's (2000) scale in order to gain a broader understanding into how participants felt about the automated system. Questions 13 to 15 and 18 were added to investigate how the level of feedback affects participants' trust in the autonomous vehicle. Questions 16, 17, 19 and 20 were added to examine the participants' intention to use and hence acceptance of the autonomous vehicle in the future. (See Appendix A) Participants were asked to select the option that best match their feelings using a 7-point Likert-type scale, with ratings that range from 1 (not at all) to 7 (extremely). These two set of questions (Jian et al., 2000 and additional) were combined to give an overall trust rating reported in this paper.

\subsection{Procedures}

Participants were given a participant information sheet, which contained details about the study, before deciding whether or not to participate. Once agreed, a consent form was given and signed. Two pre-study questionnaires were then completed. Before the study began, the participants were asked to sit comfortably in the driver seat with the seat belt fastened, aiming to replicate a realistic driving situation.

Each participant went through the same driving scenarios (10 videos) in the same order (see Table 2), but with different level of visual feedback depending on their assigned group. The participants were instructed to imagine themselves seated in an autonomous vehicle, and to pay attention to the iPad display. They were also instructed that if they felt unwell during anytime during the process, they could inform the researcher and stop the experiment. At the end of each video, a trust questionnaire was given to the participants to record their feelings of trust about the past video. Upon completion of the 10 videos, the participants were given a post-study simulator questionnaire to ensure that they were feeling fine, debriefed and thanked for the participation.

\subsection{Pilot Study}

A pilot study was conducted to assess the practicability and to identify if any procedures were required to improve the study design. A convenience sampling method was used to recruit the participant to partake in the pilot study. Identical procedures of the study design were followed. Participant information sheet, consent form, demographic and pre-study questionnaire were given. The participant was assigned as Group 3 - high feedback, as visual displays were provided both from the projector and iPad. Similarly, trust questionnaires were completed at the end of each video. Finally, the participant was given a post-study simulator questionnaire and debriefed. As a result, the study took approximately 45 minutes, and the projected screen position was lowered further down, near eye level, as participant stated it was slightly too high. Other than this, the study ran smoothly and no other changes were required.

\subsection{Data Analysis}

The aim of the study is to understand what level of visual feedback provides the most trust in users of highly automated vehicle. The primary data collected was the participants' responses to the trust questionnaires that were given at the end of each driving scenarios. In order to analyse the trust and distrust scores, questions in the trust questionnaire are separated into either trust or distrust. Questions 1 
to 5,15 and 19 are found to be related to distrust, with a maximum total trust score of 49 . Questions 6 to 14,16 to 18 and 20 are associated with trust, with a maximum total trust score of 91 . In this study, the composite scores on the measures of trust are calculated based on the technique proposed by Jian et al. (2000); firstly, the distrust questions were reversed scored, followed by the addition of all questions scores.

\section{Results}

To compare the level of trust between groups, participants trust scores in each feedback group per video were added to give a total trust score. Higher trust scores refer to a higher level of subjective trust in the automated vehicle as rated by the participants. Table 3 shows the total trust scores of participants in each feedback group per video and Figure 5 illustrates how different levels of visual feedback can have an impact on the level of trust in participants over time. Time refers to the progression of video from driving video 1 to driving video 10. The data shows that the moderate feedback group has the lowest trust scores of 851 in Video 5, followed by no feedback group with 855 in Video 1. The no feedback and high feedback groups both show a gradual inclination in trust scores, whereas the moderate feedback group exhibited the greatest fluctuation over time but resulting in near-identical scores comparing the start (906) and end (905). The high feedback group recorded the highest total trust score of 1082 in Videos 9 and 10. The graph clearly shows that the moderate feedback group resulted in the lowest trust score at Video 10 , followed by no feedback and high feedback groups, respectively. Furthermore, based on the average trust scores, the results suggest that high feedback group created the highest level of trust in participants, resulting in a mean trust score of 1046.7, whereas the moderate feedback and no feedback groups shown marginal differences, with 916.7 and 912.6, respectively (Table 3 \& Figure 6). The absence of adequate feedback has an impact on the level of trust in drivers; visual feedback with information providing what the vehicle can see and will do was found to create more trust in participants.

\begin{tabular}{|c|c|c|c|}
\hline Video Group & $\begin{array}{l}\text { Group } 1 \text { - No } \\
\text { Feedback }\end{array}$ & $\begin{array}{c}\text { Group } 2 \text { - Moderate } \\
\text { Feedback }\end{array}$ & $\begin{array}{c}\text { Group 3- High } \\
\text { feedback }\end{array}$ \\
\hline 1 - Exiting Business Park & 855 & 906 & 1013 \\
\hline 2 - Dual Carriageway & 904 & 911 & 1010 \\
\hline 3 - Small Town & 896 & 921 & 1020 \\
\hline 4 - Town Centre & 894 & 950 & 1019 \\
\hline 5 - Single Carriageway & 905 & 851 & 1038 \\
\hline $\begin{array}{l}6 \text { - Moderate Motorway } \\
\text { Traffic }\end{array}$ & 890 & 876 & 1061 \\
\hline 7-Residential Area & 933 & 957 & 1072 \\
\hline $\begin{array}{l}8 \text { - Residential Area: Blind } \\
\text { Corners }\end{array}$ & 948 & 920 & 1070 \\
\hline 9 - Merging onto Motorway & 949 & 970 & 1082 \\
\hline 10 - High Motorway traffic & 952 & 905 & 1082 \\
\hline $\begin{array}{c}\text { Mean trust scores of all } \\
\text { videos }\end{array}$ & 912.6 & 916.7 & 1046.7 \\
\hline
\end{tabular}

Table 3. Total trust scores and mean trust scores of participants in each group. 


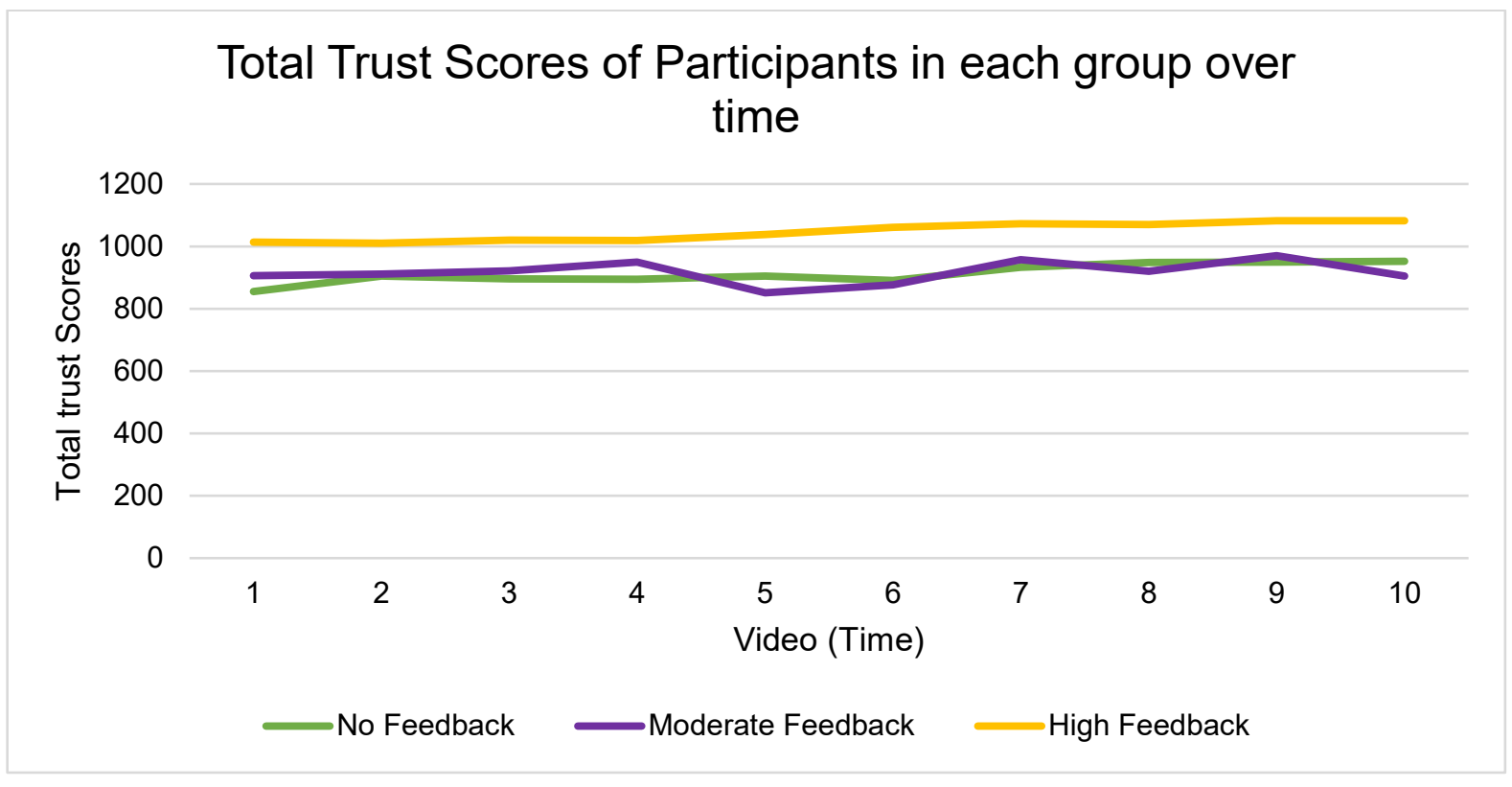

Figure 5. Total trust scores of participants between the three groups.

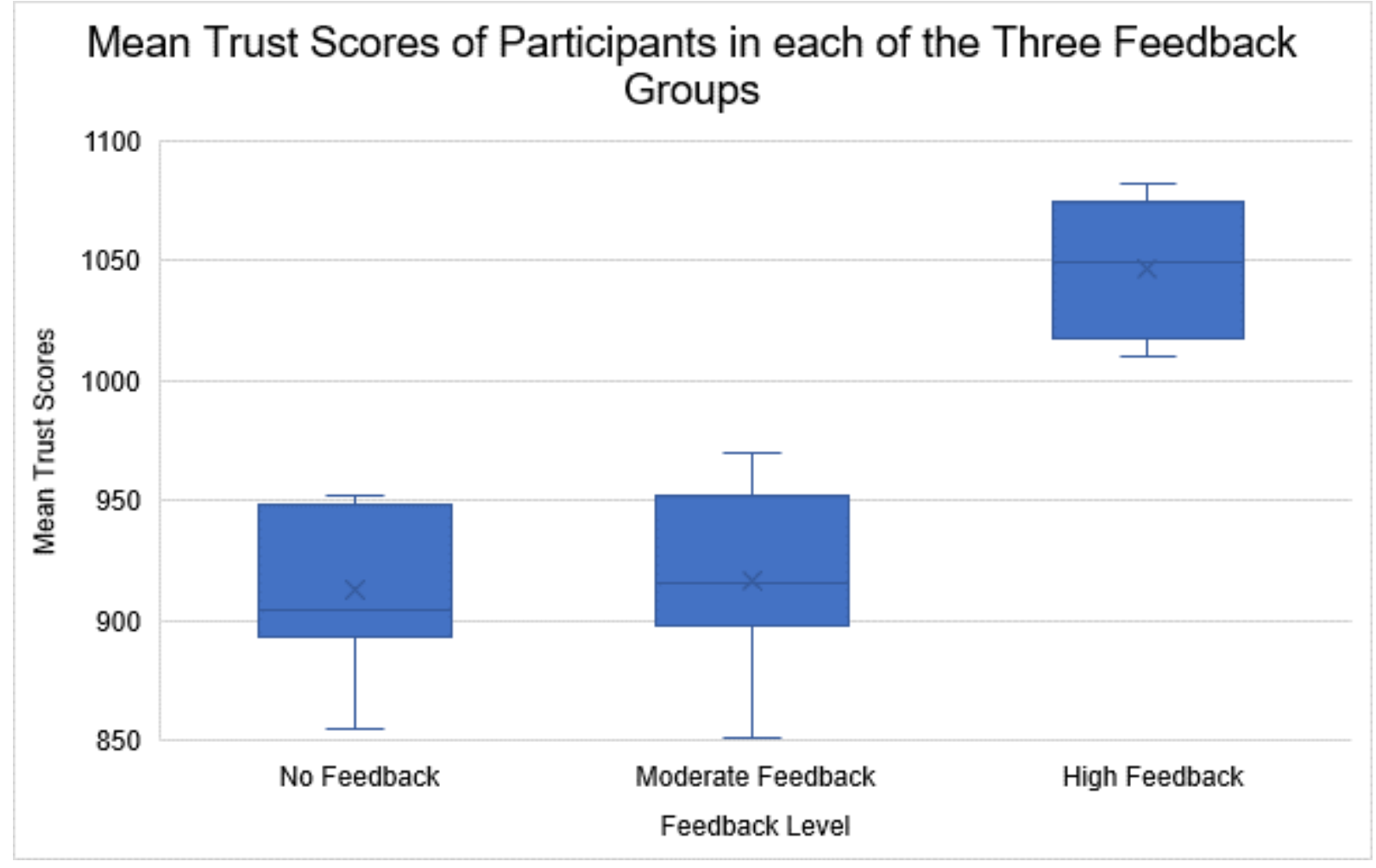

Figure 6. Mean trust scores of all videos between the three groups.

Table 4 shows the results for the Mann Whitney U Test. For statistical tests, a significance level of $\alpha=0.05$ was used. The Mann Whitney $U$ test reported that there is no significant association between 
Group 1 and Group 2, with $(p=0.481>\alpha)$. The results highlight that there was no statistically significant difference in providing no feedback and moderate feedback information to participants. However, the test report also revealed two statistically significant differences; there is a signification difference between Group 1 and Group $3(p=<0.001<\alpha)$, and between Group 2 and Group $3(p=<0.001<\alpha)$. Participants expressed greater trust in the $A D$ system with feedback that provided information about what the vehicle can see and will do than with feedback that only provided what the vehicle can see or no feedback.

\section{Mann Whitney Test}

\begin{tabular}{|l|r|r|r|}
\hline \multicolumn{5}{|c|}{ Test Statistics } \\
\hline & Group 1 - Group 2 & \multicolumn{1}{|c|}{ Group 1 - Group 3 } & \multicolumn{1}{l|}{ Group 2 - Group 3 } \\
\hline Mann-Whitney U & 40.500 & .000 & .000 \\
\hline Wilcoxon W & 95.500 & 55.000 & 55.000 \\
\hline Z & -.718 & -3.781 & -3.781 \\
\hline Asymp. Sig. (2-tailed) & .473 & .000 & .000 \\
\hline $\begin{array}{l}\text { Exact Sig. [2*(1-tailed } \\
\text { Sig.)] }\end{array}$ & .481251 & .000011 & .000011 \\
\hline
\end{tabular}

Table 4. Results for Mann-Whitney Test. Group 1: No feedback, Group 2: Moderate Feedback, Group 3: High Feedback.

\section{Discussion}

The current research investigated the influence of visual feedback (no feedback vs. moderate feedback vs. high feedback) on users' trust level in different autonomous driving scenarios. The finding suggests that the type of vehicle-to-driver communication about the vehicle's future action has an important consequence upon drivers' trust level of the vehicle in an autonomous driving situation. The result highlights that participants in the high feedback group trust the AD systems more compared to moderate feedback and no feedback groups. This finding is parallel to an earlier study conducted by Verberne et al. (2012), although the study is not completely equivalent, similar results were obtained; their study suggests that ACCs that provide information and action, which relates to high feedback in this study, are found to increase driver's acceptance and trust in automation compared to ACCs that provide just information or action, where providing just information would equate to moderate feedback in this research. However, contrary to this study's results, Koo et al. (2015) suggested that displaying 'why' messages that explained why the vehicle is responding in a certain way (e.g. "Obstacle ahead"; which relates to moderate feedback in this study), provided higher trust level compared to displaying 'how' messages that explained how the vehicle is going to respond (e.g. "Car is braking") and when both "how and why' messages (which equates to high feedback in this study) were displayed. A possible reason for the contradictory results could be due to the type of information given; in Koo et al.'s (2015) study, verbalized messages were given rather than visual information. Furthermore, this paper described how the three visual feedback levels (from low to high) can affect driver's trust level. However, recent research 
(Ulahannan et al., 2020a; Ulahannan et al., 2020b) have suggested that different people preferred different information types (High Information Preference and Low Information Preference). Ulahannan et al.'s (2020a) study highlighted that presenting different types of feedback information (status vs intent) can impact on drivers' trust level. The findings suggested that drivers looked at system transparency information over status information. Taking these into consideration, it may be important to incorporate the different types of feedback information (status vs intent) in conjunction with the level of visual feedback to investigate the level of trust in users of a highly automated vehicle in the future.

Moreover, the finding suggests that there is no significant difference between no feedback group and moderate feedback group. One possible explanation for this may be due to the increase workload in the driver, as participants in the moderate feedback group are essentially required to double check the driving sceneries with the displays. This resonates with previous literature, which indicates that higher workloads can decrease the level of trust and acceptance to use the automation (Biro et al., 2004). This finding is particularly important, as this directs to a new variable; it will be interesting to investigate whether there is a significant difference in providing only what the vehicle will do compared to the results shown here in future research.

Another Interesting finding found is that although participants in the high feedback group thought the amount of feedback given was adequate, suggestion was made to include other forms of feedback to provide a better solution as it currently reduces the ability to perform other secondary visual tasks in the vehicle, such as using a mobile phone. This aligns to the current trend found with using mobile devices when travelling to pass the time (Lyons et al., 2016). Users could be expected to become a passenger in future automated vehicles, hence have less involvement in the driving task. Previous findings demonstrate that when an individual performs two visually based tasks concurrently, they perform less well than when the tasks are performed separately as there is a limited memory capacity to do so (Baddeley \& Hitch, 1974). It is also found that performance was not affected when completing a visual based task and a non-visual based task simultaneously. Therefore, this finding suggests that providing a combination of feedback from the vehicle, such as haptic feedback, may inspire the user to perform a secondary task indicating a higher level of trust in the users.

Previous findings highlighted that trust develops and enhances over time (Yang et al., 2017). As Luhmann (1979) stated, "trust has to be achieved in a familiar world", proposing that familiarity is a requirement for trust development. In this study, familiarity relates to the current actions of the vehicle and trust is based on that previous familiar experience, which is evident in the increase in trust and decrease in distrust over time. Furthermore, responses related to the question of familiarity of the autonomous vehicle (Appendix A, Question 12) showed a non-significant, upward trend in all three groups. This clearly indicates that trust can be developed even in the absence of feedback, due to familiarity. It is possible to increase familiarity in automation and to improve the likelihood of user's acceptance and trust by 
providing, for example, knowledge about the vehicle's abilities and limitations before using the AD system through pre-training (Khastgir et al., 2018; Forster et al., 2019).

The other noticeable trend was the significant fall in subjective trust rating in video 5, 6 and 10 (single carriageway, moderate motorway traffic and high motorway traffic, respectively) in the moderate feedback group. The results reflect that trust level alters depends on the driving situation and context. Similarly, the result of a participant in the high feedback group showed that trust was developed slightly at the beginning of the experiment. However when the motorway driving scenarios were shown, they displayed loss of trust in the system. Both of these results indicate that different level of feedbacks may be required depending on the driving situation. This finding resonates with Koo et al.'s (2015) study, which indicates that different levels of feedback should be given depending on whether it is a critical or non-critical-safety situation. Perhaps offering a higher level of feedback in high traffic situations and less feedback in low traffic situations can therefore be a potential solution. This concept can be reinforced by Stanton \& Young's (2005) findings, where highest situational awareness was found when a low feedback system was provided in low traffic conditions, and when a medium feedback system was provided in medium and high traffic conditions. It is evidence from Petersen et al.'s (2019) study that ADAS that enhance situational awareness can facilitate driver's trust in automated vehicles.

\subsection{Limitations and Future Research}

As with all research there are limitations associated with the findings of this research due to the study design. Firstly, as the driving videos presented to the participants were not randomised due to practical limitations, it is understood that this does not allow generalisation of the results to other driving scenarios. It would have been useful if item analysis can be performed to determine which visual feedback type is more or less useful under certain types of driving conditions, but the authors believe this would only play a minimal role in defining the results. The authors see changes in trust level over the conditions rather than just a simple increase in trust from the pilot study, hence they believe that order effects may have no major impact on participant's trust on the AD system. However, researchers should aim to randomise the driving videos in their study design to avoid this limitation.

Secondly, the study is chosen to be carried out in a static driving simulator, the artificial conditions may affect participants' natural behaviours and responses to trust and consequently, the findings may lack generalisability to real-life autonomous vehicles. The driving scenarios were also chosen not to replicate a near-miss or accident, or present different weather conditions, as this may substantially affect one's view on autonomous vehicle. Driving scenarios with different factors should be added in future studies, with data collection in a more-realistic environment to ensure generalisation of findings to the real-world.

Finally, it is possible that the 'Hawthorne effect' (Landsberger, 1958) was present in this study. Due to practicalities of the experimental design, the researcher was sitting at the back of the vehicle to control the 
driving videos for the projected screen and the video recordings of the participants' behaviour. This means participants behaviour may be affected as they are aware of being observed and may not act fully in the way they would if they weren't, for example, it may (or may not) be that more participants will carry out secondary tasks in the absence of the experimenter.

\section{Conclusions}

To examine whether trust in autonomous vehicles changes due to the level of visual feedback, a static driving simulator study with 30 participants from three different groups (no feedback vs. moderate feedback vs. high feedback) was conducted. Based on the mean trust scores, high visual feedback was associated with the highest subjective trust rating in the autonomous vehicle compared to the other two groups. Results also showed that there is no significant association between no feedback and moderate feedback groups, but a significant increase in trust from no feedback to high feedback groups, and between moderate feedback and high feedback groups. Additionally, the research found that participants' trust level adjusts dependent on whether it is a safety or non-safety-critical situations. This is in line with a study presented by Koo et el. (2015), where it was concluded that different levels of feedback may be required in different driving conditions to inspires trust in users. Therefore, future work should also explore and identify the optimum combination between different types of feedback in certain driving conditions, such as motorway and high traffic roads, that may affect the level of trust in drivers of autonomous vehicles. Using an adaptive interface based on the driving situation might be a solution, and this can also prevent excessive information and overload which may cause misuse and hence distrust in the $A D$ system.

In order to increase familiarity and hence acceptance and trust in users of AD systems in the future, it is recommended that an iterative experience of the systems should be provided progressively. Providing knowledge via pre-training about the abilities and limitations of the system would also be beneficial (Khastgir et al., 2018; Forster et al., 2019). When the users develop familiarly and experience over time, they will be more likely to accept and trust the AD systems. However, once the driver's level of trust in the system is adjusted to an appropriate level, they may desire to reduce the level of visual feedback - hence paving the way for an Adaptive Interface. Further structuring and investigation when this might occur and how to provide such options to drivers must be explored. The findings also prompt a new variable; future research should explore whether displaying visual-only feedback that provides information on what the vehicle will do will have an effect on the driver's trust of a highly automated vehicle. 


\section{References}

Babakus, E. \& Mangold, W.G. (1992) 'Adapting the SERVQUAL scale to hospital services: An empirical investigation', Health Services Research, 26(2), pp. 767-786.

Baddeley, A.D. \& Hitch, G. (1974) Working memory. In Bower, G.H. (Ed.), The psychology of learning and motivation: Advances in research and theory, 8, pp. 47-89, New York: Academic Press.

Balfe, N., Sharples, S. \& Wilson, J.R. (2015) 'Impact of automation: measurement of performance, workload and behaviour in a complex control environment', Applied Ergonomics, 47, pp. 52-64.

Banks, V.A. \& Stanton, N.A. (2016) 'Keep the driver in control: Automating automobiles of the future', Applied Ergonomics, 53, pp. 389-395.

Beller, J., Heesen, M. \& Vollrath, M. (2013) 'Improving the driver-automation interaction: An approach using automation uncertainty', Human Factors, 55(6), pp. 1130-1141.

Biros, D. P., Daly, M. \& Gunsch, G. (2004) 'The influence of task load and automation trust on deception detection', Group Decision and Negotiation, 13(2), pp. 173-189.

Choi, J.K. \& Ji, Y.G. (2015) 'Investigating the importance of trust on adopting an autonomous vehicle', International Journal of Human-Computer Interaction, 31, pp. 692-702.

Fagnant, D.J. \& Kockelman, K. (2015) 'Preparing a nation for autonomous vehicles: opportunities, barriers and policy recommendations', Transportation Research Part A: Policy and Practice, 77: pp. 167181.

Forster, Y., Hergeth, S., Naujoks, F., Krems, J. \& Keinath, A. (2019) 'User education in automated driving: Owner's manual and interactive tutorial support mental model formation and human-automation interaction', Information 2019, 10.

Haeuslschmid, R., Buelow, M.V., Pfleging, B. \& Butz, A. (2017) 'Supporting trust in autonomous driving', in Papadopoulos, G.A. and Kuflik, T. (eds) IUI'17: proceedings of the $22^{\text {nd }}$ International conference on intelligent user interfaces companion, Limassol, Crypus, 13-16 March 2017. New York: ACM, pp. 319329.

Helldin,T., Falkman, G., Riveiro, M. \& Davidsson, S. (2013) 'Presenting system uncertainty in automotive Uls for supporting trust calibration in autonomous driving', in Osswald, S. (ed) AutomotiveUl'13: proceedings of the $5^{\text {th }}$ International conference on automotive user interfaces and interactive vehicular applications, Eindhoven, Netherlands, 28-30 October 2013, New York: ACM, pp. 210-217.

IHS Markit. (2016) Autonomous vehicle sales forecast to reach 21 mil. Globally in 2035, according to IHS Automotive. Available at: https://www.ihs.com/country-industry-forecasting.html?ID=10659115737 
Jian, J.Y., Bisantz, A.M. \& Drury, C.G. (2000) 'Foundations for an empirically determined scale of trust in automated system', International Journal of Cognitive Ergonomics, 4(1), pp. 53-71.

Khastgir, S., Birrell, S., Dhadyalla, G. \& Jennings, P. (2018) 'Calibrating trust through knowledge: Introducing the concept of informed safety for automation in vehicles', Transportation Research Part C, 96, pp. 290-303.

Koo, J., Kwac, J., Ju, W., Steinert, M., Leifer, L. \& Nass, C. (2015) 'Why did my car just do that? Explaining semi-autonomous driving actions to improve driver understanding, trust, and performance', International Journal on Interactive Design and Manufacturing, 9(4), pp. 269-275.

Landsberger, H.A. (1958) Hawthorne revisited: Management and the workers: its critics, and developments in human relations in industry vol. 9. US: Cornell University.

Lee, J.D. \& See, K.A. (2004) 'Trust in automation: Designing for appropriate reliance', Human Factors, 46 , pp. $50-80$.

Luhmann, N. (1979) Trust and Power. New York: Wiley.

Lyons, G., Jain, J., Weir, I. (2016) 'Changing times - a decade of empirical insight into the experience of rail passengers in Great Britiain', Journal of Transport Geography, 57: pp.94-104.

Lyu, N., Duan, Z., Xie, L. \& Wu, C. (2017) 'Driving experience on the effectiveness of advanced driving assistant systems', in $20174^{\text {th }}$ International Conference on Transportation Information and Safety (ICTIS), pp. 987-992.

Manawadu, U.E., Kawano, T. Murata, S., Kamezaki, M. \& Sugano, S. (2018) 'Estimating driver workload with systematically varying traffic complexity using machine learning: Experimental design', in International Conference on Intelligent Human Systems Integration, pp. 106-111.

Miller, D., Johns, M., Mok, B. Gowda, N., Sirkin, D., Lee, K. and Ju, W. (2016) 'Behavioral measurement of trust in automation: The trust fall', proceedings of the Human Factors and Ergonomics society annual meeting, Washington DC, USA, 19-23 September 2016, HFES, pp. 1849-1853.

Nielsen, J. (1994). Heuristic evaluation. In Nielsen, J., \& Mack, L. (eds), Usability inspection methods. John Wiley \& Sons, New Work.

Oliveira, L., Luton, J., Iyer, S., Burns, C., Mouzakitis, A., Jennings, P. \& Birrell., S. (2018) 'Evaluating How Interfaces Influence the User Interaction with Fully Autonomous Vehicles', in the $10^{\text {th }}$ International Conference on Automotive User Interfaces and Interactive Vehicular Applications.

Parasuraman, R. and Riley, V. (1997) 'Humans and automation: Use, Misuse, Disuse, Abuse', Human Factors, 39(2), pp. 230-253. 
Petersen, L., Robert, L. Yang, X.J. \& Tilbury, D. (2019) 'Situational awareness, driver's trust in automated driving systems and secondary task performance', SAE International Journal of Connected and Automated Vehicles, 2(2):2019.

Piechulla, W., Mayser, C. \& Gehrke, H. (2003) 'Reducing drivers' mental workload by means of an adaptive man-machine interface', Transportation Research Part F: Traffic Psychology and Behaviour, 6(4), pp. 233-248.

SAE, J3016. (2018) Taxonomy and definitions for terms related to driving automation systems for on-road motor vehicles. Available at: https://www.sae.org/standards/content/j3016_201806/

Sheridan, T.B. \& Hennessy, R.T. (1984) Research and modelling of supervisory control behaviour. Report of a workshop. Washington DC: National Research Council, Committee on Human Factors.

Sheridan, T.B. (1975) 'Considerations in modelling the human supervisory controller, International Federation of Automatic Control, Triennial World Congress, $6^{\text {th }}, 40$.

Stanton, N.A. \& Young, M.S. (2005) 'Driver behaviour with adaptive cruise control', Ergonomics, 48(10), pp. 1294-313.

Ulahannan, A., Cain, R., Thompson, S., Skrypchuk, L., Mouzakitis, A., Jennings, P. \& Birrell, S. (2020b) 'User expectations of partial driving automation capabilities and their effect on information design preferences in the vehicle', Applied Ergonomics, 82, 102969.

Ulahannan, A., Jennings, P., Oliveira, L. \& Birrell, S. (2020a) 'Designing an adaptive interface: using eye tracking to classify how information usage changes over time in partially automated vehicles', IEEE Access, vol. 8, pp. 16865-16875.

Verberne, F.M.F., Ham, J. \& Midden, C.J.H. (2012) 'Trust in smart systems: Sharing driving goals and giving information to increase trustworthiness and acceptability of smart systems in cars', Human Factors, 52(5), pp. 799-810.

Wadud, Z., MacKenzie, D. \& Leiby, P. (2016) 'Help or hindrance? The travel, energy and carbon impacts of highly automated vehicles', Transportation Research Part A: Policy and Practice, 86, pp. 1-18.

Yang, X.J., Unhelkar, V.V., Li, K. \& Shah, J.A. (2017) 'Evaluating effects of user experience and system transparency on trust in automation.', in Proceedings of the 2017 ACM/IEEE International Conference on Human-Robot Interaction, Vienna, pp. 408-416. 


\section{Appendix A}

Details of the Trust Questionnaire given to the participant after each video

\begin{tabular}{|c|c|c|c|c|}
\hline Variables & Questions & Scale & Edited from & $\begin{array}{l}\text { Trust/ Distrust } \\
\text { Question }\end{array}$ \\
\hline \multirow{12}{*}{$\begin{array}{l}\text { Trust in } \\
\text { autonomous } \\
\text { vehicle }\end{array}$} & The autonomous vehicle is deceptive & \multirow{20}{*}{$\begin{array}{l}\text { 7-point } \\
\text { Likert-type } \\
\text { scale } \\
\text { (Ratings } \\
\text { that range } \\
\text { from } 1= \\
\text { not at all, } \\
\text { to } 7= \\
\text { extremely) }\end{array}$} & \multirow{12}{*}{ Jian et al. 2000} & Distrust \\
\hline & $\begin{array}{l}\text { 02. The autonomous vehicle acts in an } \\
\text { underhanded manner }\end{array}$ & & & Distrust \\
\hline & $\begin{array}{l}\text { 03. I am suspicious of the autonomous vehicle } \\
\text { intent action }\end{array}$ & & & Distrust \\
\hline & 04. I am cautious of the autonomous vehicle & & & Distrust \\
\hline & $\begin{array}{l}\text { 05. The autonomous vehicle's actions will have a } \\
\text { damaging or injurious consequence }\end{array}$ & & & Distrust \\
\hline & 06. I am confident in the autonomous vehicle & & & Trust \\
\hline & $\begin{array}{l}\text { 07. The autonomous vehicle provides a safe } \\
\text { environment }\end{array}$ & & & Trust \\
\hline & 08. The autonomous vehicle has honesty & & & Trust \\
\hline & 09. The autonomous vehicle is dependable & & & Trust \\
\hline & 10. The autonomous vehicle is reliable & & & Trust \\
\hline & 11. I can trust the autonomous vehicle & & & Trust \\
\hline & 12. I am familiar with the autonomous vehicle & & & Trust \\
\hline HMI & $\begin{array}{l}\text { 13. The autonomous vehicle provides accurate } \\
\text { decisions }\end{array}$ & & \multirow{8}{*}{ New } & Trust \\
\hline $\mathrm{HMI}$ & $\begin{array}{l}\text { 14. The level of feedback provided by the } \\
\text { autonomous vehicle is adequate }\end{array}$ & & & Trust \\
\hline $\mathrm{HMI}$ & $\begin{array}{l}\text { 15. I was anxious that the autonomous vehicle } \\
\text { will make mistakes }\end{array}$ & & & Distrust \\
\hline $\begin{array}{l}\text { Intention to } \\
\text { use/ } \\
\text { acceptance }\end{array}$ & $\begin{array}{l}\text { 16. I would use this autonomous vehicle for } \\
\text { travelling on a daily basis }\end{array}$ & & & Trust \\
\hline $\begin{array}{l}\text { Intention to } \\
\text { use/ } \\
\text { acceptance }\end{array}$ & $\begin{array}{l}\text { 17. The autonomous vehicle enables me to } \\
\text { perform other useful tasks while driving }\end{array}$ & & & Trust \\
\hline $\mathrm{HMI}$ & $\begin{array}{l}\text { 18. The autonomous vehicle performs at a high } \\
\text { consistent level }\end{array}$ & & & Trust \\
\hline $\begin{array}{l}\text { Intention to } \\
\text { use/ } \\
\text { acceptance }\end{array}$ & $\begin{array}{l}\text { 19. I will not use the autonomous vehicle in any } \\
\text { circumstance }\end{array}$ & & & Distrust \\
\hline $\begin{array}{l}\text { Intention to } \\
\text { use/ } \\
\text { acceptance }\end{array}$ & $\begin{array}{l}\text { 20. I will consider using the autonomous vehicle } \\
\text { after drinking alcohol as a form of } \\
\text { transportation }\end{array}$ & & & Trust \\
\hline
\end{tabular}

